\title{
Clofarabine-based reduced intensity conditioning regimen with peripheral blood stem cell graft and post-transplant cyclophosphamide in adults with myeloid malignancies
}

\author{
Patrice Chevallier ${ }^{1}$, Pierre Peterlin ${ }^{1}$, Alice Garnier ${ }^{1}$, Amandine Le Bourgeois ${ }^{1}$, \\ Beatrice Mahé ${ }^{1}$, Viviane Dubruille ${ }^{1}$, Nicolas Blin ${ }^{1}$, Cyrille Touzeau ${ }^{1}$, Thomas \\ Gastinne $^{1}$, Anne Lok ${ }^{1}$, Yannick Le Bris ${ }^{2}$, Marie C. Béné ${ }^{2}$, Steven Le Gouill ${ }^{1}$, Philippe \\ Moreau $^{1}$ and Thierry Guillaume ${ }^{1}$ \\ ${ }^{1}$ Hematology Department, CHU Hotel-Dieu, Nantes, France \\ ${ }^{2}$ Hematology/Biology Laboratory, CHU Hotel-Dieu, Nantes, France \\ Correspondence to: Patrice Chevallier, email: patrice.chevallier@chu-nantes.fr \\ Keywords: allogeneic; clofarabine; post-transplant cyclophosphamide; haplo-identical; PBSC \\ Received: June 11,2018 Accepted: August 04, $2018 \quad$ Published: September 11, 2018 \\ Copyright: Chevallier et al. This is an open-access article distributed under the terms of the Creative Commons Attribution \\ License 3.0 (CC BY 3.0), which permits unrestricted use, distribution, and reproduction in any medium, provided the original author \\ and source are credited.
}

\section{ABSTRACT}

Background: The Baltimore reduced-intensity conditioning (RIC) regimen using high-dose post-transplant cyclophosphamide (PTCY) is considered as a standard of care for haploidentical allogeneic stem cell transplantation (allo-SCT). However, it is associated with relatively low survivals and high incidence of relapse, especially when considering myeloid malignancies.

Results: This retrospective study included 36 adults (males $n=18$; median age: 60.5 years old; haplodonors $n=27$; matched donors $n=8$ ) with myeloid malignancies transplanted between March 2014 and March 2017 at the University Hospital of Nantes. Very encouraging results were observed with a 18-month overall survival (OS), disease-free survival (DFS) and relapse incidence (RI) of $72 \% \pm 7.5 \%, 63.8 \pm 8 \%$, and $25 \pm 6 \%$ respectively, and a GVHD relapse-free survival (GRFS) of $52.6 \pm 8 \%$. In univariate analysis, there were no differences regarding 18-month survivals between patients allografted: i) for acute myeloid leukemia vs myelodysplastic syndrome (OS $70 \pm 11 \%$ vs $69.2 \pm 13 \%, p=0.3$; DFS $64.7 \pm 11 \%$ vs $61.5 \pm 13 \%, p=0.65$ ), or ii) with haplo-identical vs other donors (OS: $66.2 \pm 9 \%$ vs $88.8 \pm 10.4 \%, p=0.16$; DFS $59 \pm 9.5 \%$ vs $77.8 \%, p=0.6$ ).

Conclusion: The "Clo-Baltimore regimen" is safe and feasible and provides good survivals for patients with myeloid malignancies and haplo-donors.

Methods: Here, we report a variant of the Baltimore regimen, where 1) fludarabine was replaced by clofarabine, 2 ) bone marrow was replaced by peripheral blood stem cells, and 3) tacrolimus was replaced by cyclosporine, in a "Clo-Baltimore regimen".

\section{INTRODUCTION}

The Baltimore reduced-intensity conditioning (RIC) regimen using high-dose post-transplant cyclophosphamide (PTCY) is considered as a standard of care for haploidentical allogeneic stem cell transplantation (allo-SCT). However, it is associated with relatively low survivals (1-year and 2-year overall survival (OS): 46 and $36 \%$; 1-year and 2-year event-free survival (EFS): 34 and $26 \%)$ and a high incidence of relapse $(51 \%$ and $58 \%$ at 1 year and 2 years), especially when considering myeloid malignancies $(<15 \%$ of 2-year EFS) [1] Recently, more intensive conditioning regimen (myeloablative or reducedtoxicity myeloablative) have been proposed to improve 
the outcome of patients with haplo-identical donors, but this could be applied only in selected younger individuals with no co-morbidities [2]. Indeed, inferior survival has been reported for older patients receiving a myeloablative haplo-transplant compared to the use of RIC regimens [3].

Clofarabine is a second-generation purine analogue with both anti-myeloid and anti-lymphoid leukemic activity [4]. Recently, clofarabine has been used as part of fludarabine-busulfan $(\mathrm{Bu})$-based conditioning regimen instead of fludarabine. This showed very promising results with a good safety profile, both in myeloablative (CloBu4) [5] and RIC (CloBu2) [6] settings. Moreover, clofarabine also appears to have more anti-myeloid activity than fludarabine after allo-SCT [5, 7]. Here, we hypothesized that replacing fludarabine by clofarabine as part of the Baltimore regimen (Clo-Baltimore regimen) could improve the outcome of patients with (mainly) haplo-donors and myeloid malignancies ineligible for myeloablative transplant.

\section{RESULTS}

\section{Characteristics of patients}

Between March 2014 and March 2017, 36 adults (males $n=18$; median age: 60.5 years old) received the Clo-Baltimore regimen in our institution. The majority of cases suffered from acute myeloblastic leukemia (AML, $n=17$ ) or myelodysplastic syndrome (MDS, $n=13$ ). Twenty-one of them were in complete remission (CR) at transplant (AML: CR1 $n=12$; CR2 $n=4$; CR3 $n=1$; MDS: CR1 $n=3$; plasmacytoid dendritic cell neoplasm: CR1 $n=1$ ), while 15 patients were transplanted with active disease (MDS $n=10$, myelofibrosis (MF) $n=3$; chronic myeloid leukemia $n=1$, mixed MDS/ myeloproliferative syndrome $n=1$ ). Active MDS was defined by bone marrow blasts comprised between 5 and $10 \%$ at transplant. The disease risk index was retrospectively assessed according to Armand et al. [8]. The types of donor were haplo-identical $(n=27)$, sibling in 6 , matched unrelated in 2 and $9 / 10$ mis-matched unrelated in 1. Eight patients (AML $n=1$; $\operatorname{MDS} n=4$; MF $n=2$; mixed syndrome $n=1$ ) received a graft from a matched donor (sibling $n=2$, unrelated $n=6$ ) at the discretion of the physician. Characteristics of the patients are given in Table 1.

\section{Outcomes}

Except for one patient (a 60-year old female with active MDS, obesity and diabetes mellitus, haplodonor) who died during aplasia of multiple organ failure after sepsis, all patients engrafted. The median time of neutrophils $\left(>1 \times 10^{9} / \mathrm{L}\right)$ and platelets $\left(>50 \times 10^{9} / \mathrm{L}\right)$ recoveries were 18 (range: 8-27) and 28.5 (range: 11-111) days, respectively. The median number of red cell and platelet transfusions per patient during aplasia were 9 (range: 0-32) and 10 (range: 2-69), respectively. Full median donor chimerism was observed at each point evaluated between day +30 and $+90 / 100$ (peripheral blood: $99.9 \%$ (range: $41.5-100$ ) at day $+30,99.9 \%$ (range: 24-100) at day+60 and 99.9\% (range: 43-100) at day $+90 / 100$; $\mathrm{CD}^{+}$T-cells: $99.9 \%$ (range: $23-100$ ) at day+60 and $99.9 \%$ (range: $43-100$ ) at day+90/100.

With a median follow-up of 18 months for patients alive (range: 7-47), 18-month and 2-year OS were $72 \pm 7.5 \%$ and $66 \% \pm 9 \%$ (Figure $1 \mathrm{~A}$ ), while 18 -month and 2-year DFS were $63.8 \pm 8 \%$ and $52.2 \pm 10 \%$ (Figure 1B), respectively. Non-relapse-mortality (NRM) at 100 days, 1 year and 18-months were 5.5\%, 11.1\% and 11.1\%, respectively. Eleven patients have relapsed so far, with a median time between allo-SCT and relapse of 4 months (range: 2-46), including one very late relapse. The incidence of relapse at 1 -year and 18-months were both $25 \%$. The incidences of grade $2-4$ and grade $3-4$ acute GVHD (1 patient non evaluable) were $48.5 \%$ and $8.5 \%$ at day +100 , respectively (grade 2 cutaneous $n=9$; gut $n=5$, grade 3 gut $n=1$; cutaneous $n=1$; grade 4 gut $n=1)$. The incidence of 18 -months chronic GVHD (considering patients alive after day+100 $n=33$ ) was $21 \%$ (mild $6 \%$ and moderate+severe $15 \%$, including the case who received only one day of PTCY). Grade 2-4 and grade 3-4 acute GVHD rates at day +100 were 56\% and $11.1 \%$ for patients transplanted with mis-matched donors vs $25 \%$ and $0 \%$ for cases receiving a graft from a matched donor, respectively. Moreover, when excluding the patient who received only one day of PTCY, 18-months moderate/ severe chronic GVHD was $14.2 \%$ in the mismatched donor group vs $0 \%$ in the matched group. GRFS rates at 18 -months and 2-years were $52.6 \pm 8 \%$ and $40.9 \pm 9 \%$, respectively. Seven patients received donor lymphocyte infusions (DLI) at doses comprised between $1 \times 10^{5}$ and $5 \times 10^{6} \mathrm{CD}^{+} / \mathrm{kg}$, for mixed chimerism (3 MF, 1 patient obtained full chimerism), persistent positive minimal residual disease (1 CML and $1 \mathrm{AML}$, both patients obtained negative MRD) or as relapse prevention because of a highrisk disease with complex caryotype (1 MDS patient still in $\mathrm{CR}$ at 17 months and 1 AML patient still in CR at 22 months post-transplant). Only one patient developed chronic GVHD after DLI. At last follow-up (February 2018), 11 patients have died, the causes of death being relapse in 6 , dermatomyositis in 1, sepsis in 3 and grade 4 acute GVHD in 1. All patients died within 6 months post-transplant, except the patient who died from dermatomyositis at 20.5 months post-transplant. The diagnosis of dermatomyositis was difficult in this 60-year old woman allografted for a high-risk myelodysplasia in first complete remission. She didn't developed acute or chronic GVHD patient after transplant and developed dermatomyositis without any pre-existing signs of this disease or autoimmunity. It was considered as a paraneoplastic syndrome but no evidence of malignancy was documented. 


\section{Table 1: Patients characteristics}

$N=36$; Period: March 2014-March 2017

Gender : male

Median age : years (range)

Disease

Acute myeloid leukemia

Myelodysplastic syndrome

Myelofibrosis

Chronic myeloid leukemia

Myelodysplastic syndrome/myeloproliferative disease

Plasmacytoid dendritic cell neoplasm (pDC)

Disease status

Complete remission (CR) 1

CR2

CR3

Active disease

Previous allograft

Disease risk index [8]

Low

Intermediate

High

Very high

Not applicable

HCT-CI score [23]

0

1

2

3

4 or more

Donor

Median age: years (range)

Haplo-identical (son, daughter, sister, brother, father, nephew)

Sibling

Matched unrelated

Mismatch unrelated 9/10

CMV status recipient/donor:

$-/-$

$-1+$

$+/+$

$+/-$

ABO compatibility

Compatibility

Minor incompatibility

Major incompatibility

Peripheral Blood Stem Cell graft

Median CD34+ cells $/ \mathrm{kg}$
$N(\%)$

$18(50 \%)$

$60.5(31-70)$

17

13

3

1

16

4

1

15

7

2

18

14

1

1 (pDC)

3

2

11

15

5

44 (23-71)

$27(10,2,7,4,2,2)$

6

2

1

20

4

8

4

20

10

6

36

$7.09(1.45-12.11)$ 

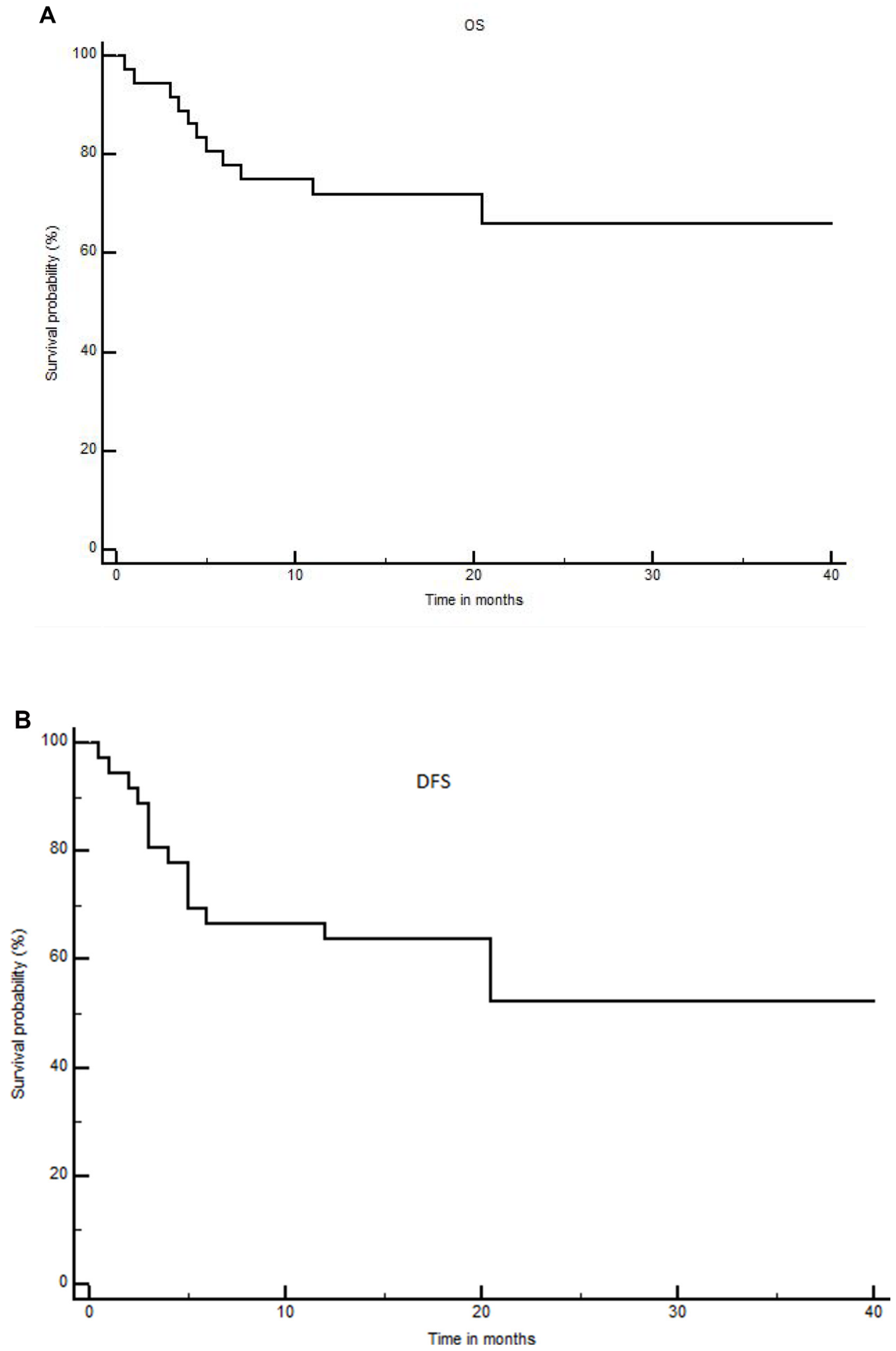

Figure 1: Overall survival (A) and disease free survival (B) for the whole cohort. 


\section{Univariate analysis}

In univariate analysis, there were no differences regarding 18-month survivals between patients allografted: i) for AML vs MDS (OS $70 \pm 11 \%$ vs $69.2 \pm 13 \%, p=0.3$; DFS $64.7 \pm 11 \%$ vs $61.5 \pm 13 \%, p=0.65$ ), or ii) with haploidentical vs other donors (OS: $66.2 \pm 9 \%$ vs $88.8 \pm 10.4 \%$, $p=0.16$; DFS $59 \pm 9.5 \%$ vs $77.8 \%, p=0.6$ ). When comparing intermediate vs high+very high DRI patients, similar relapse incidence ( $26 \%$ vs $22 \%, p=1$, DFS $(p=0.96)$ and OS $(p=0.45)$ were observed between both groups.

\section{Infections post-transplant}

One patient developed a mucormycosis infection with a favorable outcome under isavuconazole. No aspergillosis was documented. Overall, HHV-6 reactivation occurred in $67 \%$ of patients while 2 patients required rituximab for EBV reactivation and 9 patients antiviral treatment for CMV reactivation. Only one CMV disease was documented (colitis). Two patients developed adenovirus infection and 10 had symptomatic BK virus cystitis, including 1 with hemorrhage. HHV-6 infection was detected in $24(66.6 \%)$ out of the 36 patients included in the study, but no HHV6 disease was documented.

\section{Other toxicity}

One patient had a severe PTCY-related myocarditis occurring 10 days after the first dose of PTCY with a FEV at $15 \%$. This 68 -year old female allografted for a myelodysplasia with no previous cardiac events or chemotherapy treatment was transferred in intensive care unit for one month and recovered ad integrum. She's still alive at 18 months post-transplant with normal cardiac function. Also, no veno-occlusive disease was observed in this study. Only cytokine release syndrome $<=$ grade 2 were observed in this series $(n=10)$, both after haplotransplant $(n=7)$ or matched transplant $(n=3)$.

\section{DISCUSSION}

Except sequential approaches for refractory hematological malignancies, [9-12] to our knowledge, there is no series, so far, reporting the use of a clofarabinebased RIC regimen with PTCY. Here, the Clo-Baltimore regimen showed very encouraging results for patients with myeloid malignancies both in $\mathrm{CR}$ and with active disease at transplant. A lower rate of relapse was also documented, although a non myeloablative conditioning regimen was used, which is suitable for older patients and subjects with co-morbidities. This confirms the high anti-myeloid leukemic activity of clofarabine as part of a RIC regimen including not only haplo-identical but also matched/ mismatched donors. These results also compare favorably with studies reporting results of other RIC regimens in the haplo-myeloid setting $[3,13]$.

PBSC as stem cell source and ciclosporin instead of bone marrow and tacrolimus, respectively, were chosen here because of our long experience of these both modality treatments as part of clofarabine-based RIC allotransplant [6]. The incidence of acute GVHD was relatively high in our series, probably due to the use of PBSC. Clofarabine may have also participated to this high incidence, as it is known to induce mucositis [14], then contributing to potentially exposing self-antigens to donor T lymphocytes. This may lead to increased acute GVHD. However, in a previous study comparing clofarabine vs fludarabine-based RIC regimen we have shown that incidence of acute GVHD were similar between both groups [7]. There is some concern regarding the use of PBSC as source of graft in the haploidentical setting, because of this higher incidence of acute or chronic GVHD $[15,16]$. However, in the series by Ruggeri et al., [15] engraftment was higher with PBSC (95\% vs $92 \%$, $P<0.001)$ while NRM was similar between PBSC and bone marrow (BM). In the series by Bashey et al., [16] the median times to neutrophil and platelet recovery were slower after transplantation of BM compared with PB (17 v 16 days for neutrophils, $P<.001$; and 26 v 25 days for platelets, $P=.03$ ) while again NRM was similar between both groups. Of note, NRM at day 100 and 1 year $(<6 \%$ and $11 \%)$ were in the range of data published previously $[17,18]$, suggesting a low toxicity of our procedure. Similar survivals have been documented also using either PBSC or BM but a lower incidence of relapse have been reported using PBSC for haploidentical alloSCT, especially in leukemic patients [16]. Here the use of PBSC for each patient may explain also the could results regarding the relatively low incidence of relapse overall.

Although this is a small cohort, the results are very interesting for patients with matched donors, not only in terms of survivals but also regarding the incidence of GVHD, even using PBSC. The role of PTCY is probably determinant and its use as a sole GVHD prophylaxis has been already proven to be efficient in the myeloablative setting with matched donors $[19,20]$. We are currently testing this hypothesis with the Clo-Baltimore approach for matched donors as well (https://clinicaltrials.gov/ \# NCT03263767).

The role of DLI is still controversial after haploidentical allo-SCT because of a suspected higher risk of GVHD occurrence. However, lower doses of $\mathrm{CD}^{+}$T-cells are generally infused [18]. Surprisingly, we observed a very late relapse in our cohort, suggesting that a preventive treatment for disease re-occurrence could be appropriate after a Clo-Baltimore regimen-conditioned AlloSCT, as reported here. Prophylactic DLI associated or not to 5-azacytidine may help improve patients outcomes [21, 22]. 
In conclusion, the Clo-Baltimore RIC regimen appears to be an effective platform for older patients with both haploidentical or matched donors and should be considered in the future for prospective and comparative studies in allo-SCT.

\section{MATERIALS AND METHODS}

\section{Study design}

This retrospective study included all adults $(>=18$ years old) who received a Clo-Baltimore regimen for myeloid malignancies at the University Hospital of Nantes. All patients had contra-indications to myeloablative conditioning regimen. Use of the Clo-Baltimore regimen instead of the Baltimore regimen started in 2014 in our department when considering haplo-identical transplantation for myeloid hematological diseases because of our good experience with clofarabine in the matched setting [6]. All patients provided informed consent for data collection before the allo-SCT. This retrospective study was approved by the Ethics Hematology review board of the CHU of Nantes.

\section{Conditioning regimen, source of graft and supportive care}

The Clo-Baltimore regimen (Figure 2) consisted of Clofarabine $30 \mathrm{mg} / \mathrm{m}^{2} /$ day on days -6 to -2 , cyclophosphamide $14.5 \mathrm{mg} / \mathrm{kg}$ on day -6 , low dose total body irradiation 2 Grays on day-1. All patients received PTCY $50 \mathrm{mg} / \mathrm{kg} /$ day on days +3 and +4 , except one who had a matched donor and received only one day of PTCY. Further GVHD prophylaxis consisted in cyclosporine A and mycophenolate mofetil initiated on day +5 . G-CSF was also administered systematically from day +5 on, until the end of aplasia. All patients received PBSC as stem cell source on day 0 , fluconazole as fungal prophylaxis and i.v. immunoglobulins once a week until day +100 as infection prevention.

\section{Statistical analyses}

The clinical outcomes studied were 18-month and 2-year overall survival (OS), disease-free survival (DFS), relapse incidence (RI) and non-relapse mortality (NRM). OS was defined as the time from day 0 of allo-SCT to death or last follow-up for survivors. DFS was defined as time from day 0 of allo-SCT to time without evidence of relapse or disease progression censored at the date of death or last follow-up. Relapse was defined as any event related to re-occurrence of the disease. NRM was defined as death from any cause without previous relapse or progression. Probabilities of OS and DFS were calculated using the log-rank test and Kaplan-Meier graphical representation. Acute and chronic GVHD were diagnosed and graded according to standard criteria $[24,25]$ The GVHD-free/ relapse-free survival (GRFS), defined as alive with no previous grade III-IV aGvHD, no moderate or severe chronic GVHD and no relapse [26], was also studied. Univariate analyses were performed using the log rank test for OS and DFS. A $p$ value $<0.05$ was considered as statistically significant. Analyses were performed using the Medcalc ${ }^{\circledR}$ software (Ostend, Belgium).



PTCY $50 \mathrm{mg} / \mathrm{kg} /$ day on days +3 and +4

All patients received PBSC as stem cell source on day 0

Figure 2: Differences between the Baltimore regimen and the Clo-Baltimore regimen used in the study (adapted from

Luznik et al. [1]). Abbreviations: PBSC: peripheral blood stem cells; PTCY: post-transplant cyclophosphamide 


\section{Author contributions}

PC designed, performed, and coordinated the research, collected, analyzed, interpreted the data, and wrote the manuscript.

MCB performed statistical analyses, produced the figures, and commented on the manuscript.

YLB performed chimerism analyses and commented on the manuscript.

PP, AG, ALB, BM, VD, NB, CT, TG, AL, YLB, SLG, PM and TG included patients, contributed data and commented on the manuscript.

\section{CONFLICTS OF INTEREST}

All authors declare no potential financial conflicts.

\section{REFERENCES}

1. Luznik L, O'Donnell PV, Symons HJ, Chen AR, Leffell MS, Zahurak M, Gooley TA, Piantadosi S, Kaup M, Ambinder RF, Huff CA, Matsui W, Bolaños-Meade J, et al. HLAhaploidentical bone marrow transplantation for hematologic malignancies using nonmyeloablative conditioning and high-dose, posttransplantation cyclophosphamide. Biol Blood Marrow Transplant. 2008; 14:641-50.

2. Jethava YS, Sica S, Savani B, Socola F, Jagasia M, Mohty M, Nagler A, Bacigalupo A. Conditioning regimens for allogeneic hematopoietic stem cell transplants in acute myeloid leukemia. Bone Marrow Transplant. 2017; 52:1504-1511.

3. Slade M, DiPersio JF, Westervelt P, Vij R, Schroeder MA, Romee R. Haploidentical Hematopoietic Cell Transplant with Post-Transplant Cyclophosphamide and Peripheral Blood Stem Cell Grafts in Older Adults with Acute Myeloid Leukemia or Myelodysplastic Syndrome. Biol Blood Marrow Transplant. 2017; 23:1736-1743.

4. Robak P, Robak T. Older and new purine nucleoside analogs for patients with acute leukemias. Cancer Treat Rev. 2013; 39:851-61.

5. Alatrash G, Thall PF, Valdez BC, Fox PS, Ning J, Garber HR, Janbey S, Worth LL, Popat U, Hosing C, Alousi AM, Kebriaei P, Shpall EJ, et al. Long-Term Outcomes after Treatment with Clofarabine \pm Fludarabine with Once-Daily Intravenous Busulfan as Pretransplant Conditioning Therapy for Advanced Myeloid Leukemia and Myelodysplastic Syndrome. Biol Blood Marrow Transplant. 2016; 22:1792-1800.

6. Chevallier P, Labopin M, Socié G, Tabrizi R, Furst S, Lioure B, Guillaume T, Delaunay J, de La Tour RP, Vigouroux S, El-Cheikh J, Blaise D, Michallet M, et al. Results from a clofarabine-busulfan-containing, reducedtoxicity conditioning regimen prior to allogeneic stem cell transplantation: the phase 2 prospective CLORIC trial. Haematologica. 2014; 99:1486-91.
7. Chevallier P, Labopin M, de La Tour RP, Lioure B, Bulabois CE, Huynh A, Blaise D, Turlure P, Daguindau E, Maillard N, Yakoub-Agha I, Guillerm G, Delage J, et al; SFGM-TC. Clofarabine versus fludarabine-based reduced-intensity conditioning regimen prior to allogeneic transplantation in adults with AML/MDS. Cancer Med. 2016; 5:3068-3076.

8. Armand P, Kim HT, Logan BR, Wang Z, Alyea EP, Kalaycio ME, Maziarz RT, Antin JH, Soiffer RJ, Weisdorf DJ, Rizzo JD, Horowitz MM, Saber W. Validation and refinement of the Disease Risk Index for allogeneic stem cell transplantation. Blood. 2014; 123:3664-71.

9. Tischer J, Stemmler HJ, Engel N, Hubmann M, Fritsch S, Prevalsek D, Schulz C, Zoellner AK, Bücklein V, Hill W, Ledderose G, Hausmann A. Feasibility of clofarabine cytoreduction followed by haploidentical hematopoietic stem cell transplantation in patients with relapsed or refractory advanced acute leukemia. Ann Hematol. 2013; 92:1379-88.

10. Zoellner AK, Fritsch S, Prevalsek D, Engel N, Hubmann M, Reibke R, Rieger CT, Hellmuth JC, Haas M, Mumm F, Herold T, Ledderose G, Hiddemann W, et al. Sequential therapy combining clofarabine and T-cell-replete HLAhaploidentical haematopoietic SCT is feasible and shows efficacy in the treatment of refractory or relapsed aggressive lymphoma. Bone Marrow Transplant. 2015; 50:679-84.

11. Takagi M, Ishiwata Y, Aoki Y, Miyamoto S, Hoshino A, Matsumoto K, Nishimura A, Tanaka M, Yanagimachi M, Mitsuiki N, Imai K, Kanegane H, Kajiwara M, et al. HLA haploidentical hematopoietic cell transplantation using clofarabine and busulfan for refractory pediatric hematological malignancy. Int J Hematol. 2017; 105:686-691.

12. Rakszawski K, Miki K, Claxton D, Wagner H, Shike H, Mineishi S, Naik S. Clofarabine followed by haploidentical stem cell transplant using fludarabine, busulfan, and totalbody irradiation with post-transplant cyclophosphamide in non-remission AML. Int J Hematol. 2018; 108:348-350. https://doi.org/10.1007/s12185-018-2431-5.

13. Devillier R, Legrand F, Rey J, Castagna L, Fürst S, Granata A, Charbonnier A, Harbi S, d'Incan E, Pagliardini T, Faucher C, Lemarie C, Saillard C, et al. HLA-Matched Sibling Vs. Unrelated Vs. Haploidentical Related Donor Allogeneic Hematopoietic Stem Cell Transplantation for Patients Aged Over 60 Years with Acute Myeloid Leukemia: a Single-Center Donor Comparison. Biol Blood Marrow Transplant. 2018; 24:1449-1454. https://doi.org/10.1016/j. bbmt.2018.02.002.

14. Farag SS, Wood LL, Schwartz JE, Srivastava S, Nelson RP Jr, Robertson MJ, Abonour R, Secrest A, Cox E, Baute J, Sullivan C, Kane K, Jones DR. Phase I trial and pharmacokinetic study of high-dose clofarabine and busulfan and allogeneic stem cell transplantation in adults with high-risk and refractory acute leukemia. Leukemia. 2011; 25:599-605.

15. Ruggeri A, Labopin M, Bacigalupo A, Gülbas Z, Koc Y, Blaise D, Bruno B, Irrera G, Tischer J, Diez-Martin JL, 
Castagna L, Ciceri F, Mohty M, et al. Bone marrow versus mobilized peripheral blood stem cells in haploidentical transplants using posttransplantation cyclophosphamide. Cancer. 2018; 124:1428-1437.

16. Bashey A, Zhang MJ, McCurdy SR, St Martin A, Argall T, Anasetti C, Ciurea SO, Fasan O, Gaballa S, Hamadani M, Munshi P, Al Malki MM, Nakamura R, et al. Mobilized Peripheral Blood Stem Cells Versus Unstimulated Bone Marrow As a Graft Source for T-CellReplete Haploidentical Donor Transplantation Using Post-Transplant Cyclophosphamide. J Clin Oncol. 2017; 35:3002-3009.

17. Castagna L, Bramanti S, Furst S, Giordano L, Crocchiolo R, Sarina B, Mauro E, Morabito L, Bouabdallah R, Coso D, Balzarotti M, Broussais F, El-Cheikh J, et al. Nonmyeloablative conditioning, unmanipulated haploidentical SCT and post-infusion CY for advanced lymphomas. Bone Marrow Transplant. 2014; 49:1475-80.

18. O'Donnell PV, Eapen M, Horowitz MM, Logan BR, DiGilio A, Brunstein C, Fuchs EJ, Flowers ME, Salit R, Raj K, Pagliuca A, Bradstock K, Granata A, et al. Comparable outcomes with marrow or peripheral blood as stem cell sources for hematopoietic cell transplantation from haploidentical donors after non-ablative conditioning: a matched-pair analysis. Bone Marrow Transplant. 2016; 51:1599-1601.

19. Kanakry CG, O'Donnell PV, Furlong T, de Lima MJ, Wei W, Medeot M, Mielcarek M, Champlin RE, Jones RJ, Thall PF, Andersson BS, Luznik L. Multi-institutional study of post-transplantation cyclophosphamide as single-agent graft-versus-host disease prophylaxis after allogeneic bone marrow transplantation using myeloablative busulfan and fludarabine conditioning. J Clin Oncol. 2014; 32:3497-505.

20. Jacoby E, Chen A, Loeb DM, Gamper CJ, Zambidis E, Llosa NJ, Huo J, Cooke KR, Jones R, Fuchs E, Luznik L, Symons HJ. Single-Agent Post-Transplantation Cyclophosphamide as Graft-versus-Host Disease Prophylaxis after Human Leukocyte Antigen-Matched Related Bone Marrow Transplantation for Pediatric and Young Adult Patients with Hematologic Malignancies. Biol Blood Marrow Transplant. 2016; 22:112-8.
21. Goldsmith SR, Slade M, DiPersio JF, Westervelt P, Schroeder MA, Gao F, Romee R. Donor-lymphocyte infusion following haploidentical hematopoietic cell transplantation with peripheral blood stem cell grafts and PTCy. Bone Marrow Transplant. 2017; 52:1623-1628.

22. Guillaume T, Yakoub-Agha I, Tabrizi R, Borel C, Chevallier P, Magro L, Vigouroux S, Peterlin P, Garnier A, Rubio MT, Huynh A, Milpied N, Moreau P, et al. Prospective Phase II Study of Prophylactic Azacitidine and Donor Lymphocyte Infusions Following Allogeneic Hematopoietic Stem Cell Transplantation for High Risk Acute Myeloid Leukemia and Myelodysplastic Syndrome. Blood. 2016; 128:1162; (ASH Meeting 2016). http://www.bloodjournal.org/ content/128/22/1162.

23. Sorror ML, Maris MB, Storb R, Baron F, Sandmaier BM, Maloney DG, Storer B. Hematopoietic cell transplantation (HCT)-specific comorbidity index: a new tool for risk assessment before allogeneic HCT. Blood. 2005; 106:2912-9.

24. Harris AC, Young R, Devine S, Hogan WJ, Ayuk F, Bunworasate U, Chanswangphuwana C, Efebera YA, Holler E, Litzow M, Ordemann R, Qayed M, Renteria AS, et al. International, Multicenter Standardization of Acute Graft-versus-Host Disease Clinical Data Collection: A Report from the Mount Sinai Acute GVHD International Consortium. Biol Blood Marrow Transplant. 2016; 22:4-10.

25. Filipovich AH, Weisdorf D, Pavletic S, Socie G, Wingard JR, Lee SJ, Martin P, Chien J, Przepiorka D, Couriel D, Cowen EW, Dinndorf P, Farrell A, et al. National Institutes of Health consensus development project on criteria for clinical trials in chronic graft-versus-host disease: I. Diagnosis and staging working group report. Biol Blood Marrow Transplant. 2005; 11:945-56.

26. Ruggeri A, Labopin M, Ciceri F, Mohty M, Nagler A. Definition of GvHD-free, relapse-free survival for registrybased studies: an ALWP-EBMT analysis on patients with AML in remission. Bone Marrow Transplant. 2016; 51:610-1. 